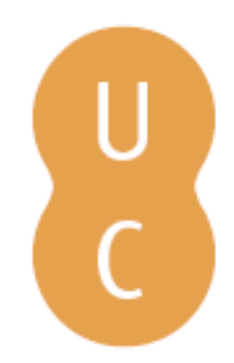

\title{
pommalina
}

\section{Diversos aspectos de la tradición clásica en El carnaval del diablo de Juan Oscar Ponferrada}

\author{
Autor(es): $\quad$ Herrera Alfaro, Ariel Arturo \\ Publicado por: Imprensa da Universidade de Coimbra; Annablume \\ URL \\ persistente: URI:http://hdl.handle.net/10316.2/40923 \\ DOI: $\quad$ DOI:https://doi.org/10.14195/978-989-26-1298-0_17 \\ Accessed : $\quad$ 26-Apr-2023 14:58:29
}

A navegação consulta e descarregamento dos títulos inseridos nas Bibliotecas Digitais UC Digitalis, UC Pombalina e UC Impactum, pressupõem a aceitação plena e sem reservas dos Termos e Condições de Uso destas Bibliotecas Digitais, disponíveis em https://digitalis.uc.pt/pt-pt/termos.

Conforme exposto nos referidos Termos e Condições de Uso, o descarregamento de títulos de acesso restrito requer uma licença válida de autorização devendo o utilizador aceder ao(s) documento(s) a partir de um endereço de IP da instituição detentora da supramencionada licença.

Ao utilizador é apenas permitido o descarregamento para uso pessoal, pelo que o emprego do(s) título(s) descarregado(s) para outro fim, designadamente comercial, carece de autorização do respetivo autor ou editor da obra.

Na medida em que todas as obras da UC Digitalis se encontram protegidas pelo Código do Direito de Autor e Direitos Conexos e demais legislação aplicável, toda a cópia, parcial ou total, deste documento, nos casos em que é legalmente admitida, deverá conter ou fazer-se acompanhar por este aviso.

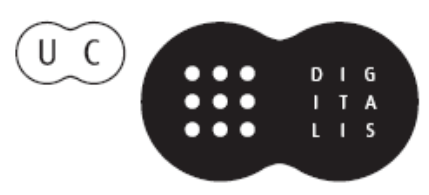




\section{O Livro do Tempo: \\ Escritas e reescritas}

\section{Teatro Greco-Latino e sua recepção II}

Maria de Fátima Silva, Maria do Céu

Fialho \& José Luís Brandão (coords.)

IMPRENSA DA UNIVERSIDADE DE COIMBRA 


\title{
Diversos aspectos de la tradición ClÁsica en EL CARNAVAL Del Diablo de Juan Oscar Ponferrada (Different aspects of Classical tradition in Evil's Carnival by Juan Oscar Ponferrada)
}

\author{
Ariel Arturo Herrera Alfaro (aher74@yahoo.com.ar) \\ Universidad Nacional de Catamarca, Argentina
}

\begin{abstract}
Resumen - La obra literaria de Juan Oscar Ponferrada responde a una conjunción de cuatro aspectos vinculados con su educación y sus preferencias literarias: los clásicos grecorromanos, el folklore del Noroeste Argentino, la devoción religiosa y el teatro español del s. XX. En la obra teatral El carnaval del diablo, estrenada en 1943, estos aspectos aparecen fusionados con gran nivel estético y capacidad creadora. Por esto mismo, es difícil separar los elementos que pertenecen a cada una de estas tradiciones y, sobre todo, porque la obra se presenta como un texto predominantemente folklórico. Sin embargo, hay indicios y evidencias que permiten establecer vínculos con el teatro de la Antigüedad. En este trabajo se revisa aquellos elementos que pertenecerían a la tradición clásica, la manera en que se presentan, los sentidos parciales que adquieren y un bosquejo de su incidencia en el sentido total de esta obra.
\end{abstract}

Palabras clave - Teatro, carnaval, Baco, Pucllay, Chiqui.

Aвstract - Juan Oscar Ponferrada's literary work is the result of a conjunction of four aspects related to his education and his literary preferences: the classics, the folklore from northwestern Argentina, his religious devotion and $20^{\text {th }} \mathrm{c}$. Spanish theatre. In his play El carnaval del diablo, premiered in 1943, these aspects are merged with skilful creativity and at a great aesthetic level. Thus, it is difficult to distinguish the elements from these different traditions, above all because the play seems to be predominantly a folk text. However, there is some evidence that may allow links to be established with classical theatre. In this paper, elements pertaining to the classical tradition, the way they are presented and the senses they acquire are revised, as well as their incidence on the global sense of the play.

Keywords - Theatre, carnaval, Bacchus, Pucllay, Chiqui.

"Le Théâtre a deux Masques -Tragedie-Comédiecelui qui pleure et celui qui rit, souvent séparé et quelquefois accouplé."

Paul de Saint-Victor

\section{INTRODUCCIÓN}

La obra literaria de Juan Oscar Ponferrada ${ }^{1}$ responde a una conjunción de

\footnotetext{
${ }^{1}$ Nació en Catamarca, Argentina, en 1907. Falleció en Buenos Aires en 1990.
} 
cuatro aspectos vinculados con su formación, su tradición familiar y sus preferencias literarias, esto es, el conocimiento de los clásicos grecorromanos, el ahondamiento en el folklore del Noroeste Argentino, la devoción religiosa de tradición familiar y el teatro español, particularmente, del s. XX. En su obra teatral El carnaval del diablo, estrenada en 1943, estos aspectos aparecen fusionados con gran nivel estético y capacidad creadora. Por esto mismo, es difícil separar los elementos que pertenecen a cada una de estas tradiciones y, sobre todo, porque la obra se presenta como un texto predominantemente folklórico. Sin embargo, hay indicios y evidencias que permiten establecer vínculos con diversos aspectos del teatro de la Antigüedad.

La primera motivación para iniciar la indagación de esta obra desde la perspectiva del teatro clásico y su recepción, surge de la inmediata sensación que deja en el lector (ya que en la puesta en escena puede sufrir diversas modificaciones), la de haber asistido a un drama culturalmente rico, estructuralmente complejo y de planteos esenciales acerca de la vida y la muerte, la alegría y la desgracia, el amor y el odio, o relaciones cruzadas de estas dualidades como amor-muerte, desgracia-liberación. Entre otras, éstas son situaciones límites que arraigan en los hombres de todos los tiempos y, en esta obra, han sido presentadas dramáticamente con toda la fuerza de una tragedia.

El presente trabajo es la parte inicial de una serie de estudios sobre los componentes de tradición clásica en esta obra para introducir la edición facsimilar del manuscrito que tenemos en preparación. Por lo tanto, el objetivo de esta comunicación es, por un lado, presentar una lista de aquellos elementos de raíz clásica a nivel de estructura dramática, de sentidos parciales y de conjunto, y, por otro, bosquejar los niveles de incidencia en la comprensión de la obra deteniéndonos en el comentario de pocos ejemplos.

\section{Mención de Antecedentes}

Posiblemente, el primero en percibir y señalar las relaciones entre $\mathrm{El} \mathrm{car-}$ naval del diablo y la cultura clásica, en particular, con lo esencial de la tragedia griega, fue Leonardo Castellani muy poco después de estrenada la obra y en un artículo reunido más tarde en libro apenas dos años del estreno (cf. Castellani 1945: 298-301). Bajo el titulo "El carnaval del diablo", el breve escrito elogia la obra y critica a los que no habían sabido apreciarla ${ }^{2}$; allí anota consideraciones importantes relacionadas con el teatro griego:

\footnotetext{
2 "Es doloroso comprobar la incapacidad o inhonestidad de la crítica oficial que dispone la Argentina de los grandes vehículos publicitarios: ante una obra que es lo mejor que ha dado el teatro argentino en muchos años, la crítica ha claudicado unánimemente. ¿Está pasando la Argentina por una crisis de la inteligencia; o es que existe la inteligencia y está amordazada y suplantada por la mistificación y la espuriedad?” (Castellani 1945: 300).
} 
Sin tentar comparaciones imposibles, esta tragedia moderna [El carnaval del diablo] recuerda los nombres más grandes y es de la cepa del más puro teatro griego. La esencia de la tragedia consiste en la presencia de una fuerza supracósmica por encima del libre juego de los albedríos humanos, que empuña la acción desde el principio con fuerza irrompible; y en la purificación final y la ruptura del conflicto insoluble por medio del dolor y la catástrofe. Ponferrada ha tenido esos dos caracteres del género teatral supremo [...]. (Castellani 1945: 298)

Otro de los estudiosos del teatro de Juan Oscar Ponferrada que merece ser mencionado fue el profesor José Horacio Monayar quien, en su abundantísima prosa española, ha reconocido que El carnaval del diablo merecía ser relacionado con el teatro clásico en su aspectos esenciales (cf. Monayar 1993: 197-211).

Hay otros artículos que, sin tratar específicamente el tema, dejan algunas líneas que advierten estas relaciones en el sentido que nos interesa aquí ${ }^{3}$. Pero no vamos a detenernos en ellos para pasar rápidamente al asunto central de esta comunicación.

\section{Diversos vínculos}

El carnaval del diablo pone en escena lo que acontece a unos pobladores de la montaña durante los preparativos, el desarrollo y el fin del carnaval del Norte argentino. Se supone que ocurre en las primeras décadas de 1900. Particularmente, el mayor conflicto se centra en el núcleo de la familia que presta su casa para el festejo, cuyos integrantes son básicamente María Selva y Cruz (esposos), su hija Isabel y Encarnación, hermana de Cruz. En esos días de fiesta, la protagonista María Selva se reencuentra casualmente con un amor de hace unos quince años atrás, pero ahora su vida familiar y social está hecha y estable: tiene esposo, una hija, una holgada posición económica y una finca con peones. Parece una trama muy común; no lo es: María Selva es un personaje complejo, aparece como una mujer muy severa que desprecia viva voce las manifestaciones populares como las del carnaval. Por el contrario, su hija adolescente, Isabel, disfruta enormemente de esa fiesta que, justo ese año, se hace en su propia casa. Una de las tensiones dramáticas de importancia se origina cuando un peón que no es de ese pueblo (El Forastero) llega a pedir trabajo; ese hombre fue hace mucho tiempo el amor de María Selva. Él, luego del imprevisto encuentro, le hace saber que aquel sentimiento amoroso continúa, pero ella niega que en el presente le esté ocurriendo lo mismo por él y le exige mantener la distancia entre patrona y peón. La relación escénica entre ellos es de un odi et amo (Cat. 85), dicho explícitamente por María Selva ${ }^{4}$ El vínculo entre ellos es mucho mayor,

\footnotetext{
${ }^{3}$ Véase Tacconi 2004 y Barcia 2007; también Herrera 2007.

4 "María Selva. - [...] Pero todo fue oírlo y echar brotes de nuevo, porque lo odio y lo
} 
pues Isabel es hija de ambos, pero el forastero no lo sabe. La adolescente, Isabel, menosprecia el pueblo y a los pretendientes del entorno, y aspira a enamorarse de un hombre distinto a los que tiene cerca y que constantemente la buscan. Por esto mismo, siente una inmediata atracción por el recién llegado y él, por verdadero interés o por despecho, le corresponderá al ser rechazado por María Selva. Esta incipiente relación, que amenaza ser incestuosa, desencadenará el final trágico.

A lo largo del desarrollo de este drama, se hace evidente una serie de elementos que arraigan en el teatro clásico, sin mayor análisis ni forzando su reconocimiento; los principales son:

1- Inclusión de un prólogo dramático, es decir, como parte constitutiva de la obra y en el cual queda expuesta y explicada la clave para entender la unidad tragicómica de la obra. El diálogo entre dioses que explican aspectos decisivos hace pensar, por ejemplo, en el prólogo del Anfitrión de Plauto.

2- Entorno báquico, que el dramaturgo buscó conferir desde las primeras acotaciones para que las acciones quedaran imbuidas en ese ambiente.

3- El coro de jóvenes, presente en todo momento, recoge la lírica popular folklórica (es decir, la copla y la vidala) y, con ella, entra en escena una gama de matices: humorísticos, eróticos, descriptivos, de lamento, etc.

4- El semicoro de ancianos, siempre recitado y de tono serio, cuya función es la reflexión de la situación dramática, como en una suerte de diálogo con el personaje.

5- Incorporación de danzas y movimientos rituales y festivos de origen popular, por ejemplo, los topamientos, el palito, la zamba, el malambo.

6- El reconocimiento de la situación por parte de los personajes, en particular de la protagonista, presentado como un proceso gradual que agrava paulatinamente la complejidad de la trama hasta el desenlace trágico. En este sentido, viene a la memoria el progreso de la trama de Edipo Rey de Sófocles.

7- La concepción del linaje trágico, es decir, los errores o males de los antepasados se proyectan, sufren y pagan en las generaciones posteriores como una desgracia inevitable 5 . Podemos pensar, como ejemplo, en el destino de los hijos de Edipo.

8- La acción está enmarcada por el canto del coro en el inicio y la voz de un cantor al final.

quiero sin remedio y estoy atada a usted sin salvación...” (Acto III, escena VIII). Para las citas de la obra, empleamos la edición de 1970 (véase infra, Bibliografía) porque el texto está más pulido gráficamente: los actos están divididos en escenas y, además, cuenta con las partituras de las partes cantadas.

${ }^{5}$ Señalado por Tacconi 2004:192. Ejemplo: “¡Tenía que suceder, porque está dicho: / la mala sangre siempre se traiciona” (Act. IV esc. V). Esto dice un personaje refiriéndose a que la hija va a sufrir las desgracias de la madre, va a repetir los mismos errores sólo por llevar la misma sangre. 
9- La presencia de figuras míticas, dioses que provienen de ritos ancestrales y de fiestas populares que, si bien no tienen mayor actuación en la obra, ejercen su fuerza para que los hechos cotidianos tengan otro plano de significación.

10- Las constantes alusiones y reiteraciones a las fuerzas del destino como la causa inevitable de las desgracias ${ }^{6}$.

De todos estos, que son los más visibles, vamos a detenernos en un aspecto que puede resultar escurridizo, esto es, explicar algunas posibles motivaciones que tuvo el dramaturgo Juan Oscar Ponferrada para que su obra de teatro recogiera características pre-teatrales dentro de una estructura cuyos elementos recuerdan la tragedia griega. En otras palabras, a qué elementos recurrió para que esta obra indudable y deliberadamente arraigara en parámetros culturales de antigua raigambre.

\section{El "Prólogo" de El carnaval del diablo}

En el "Prólogo" que, como ya dijimos, forma parte de la obra, es posible señalar indicios y ejemplos de que el mismo Ponferrada se preocupó por especificar sus intenciones técnicas y compositivas para generar una atmósfera de teatro clásico. Está compuesto por sólo dos escenas y se inicia con la entrada de unos cosechadores de algarroba, quienes se acercan cantando. Ellos conforman el coro danzante y los semicoros, movimiento que recuerda una párodos trágica. La primera escena se cierra con el alejamiento de este grupo de cantores y recitadores. Desde este primer momento, coro y semicoro proveen de un trasfondo a la obra: las vísperas del carnaval y un amor trágico, todo lo cual está expresado en un lenguaje lírico popular y alusivo, que va de lo explícito a lo sugerente. Por ejemplo:

Coro

Algarrobo, algarrobal:

¡qué gusto me dan tus ramas

Cuando empiezan a brotar,

Señal que viene llegando

El tiempo del carnaval (Prol. esc. I)

Coro

Algarrobo, algarrobal:

La vidala por la noche

Sale a cantar y llorar:

Sale a cantar y llorar

${ }^{6}$ La mayoría de las veces, la insistencia está dicha por la protagonista María Selva, por ejemplo: "porque es fatal y está visto / que nadie puede llegar / más allá de su destino!" (Act. IV esc. VIII), “Todo lo que ha pasado es mi destino” (Act. IV esc. XIV). 
Con el tambor de la luna

Y el amor del carnaval. (Prol. esc. I)

En estos versos, los términos "algarrobo", "cantar", "llorar", "amor", "carnaval” adelantan sutilmente la mezcla de alegría y dolor que tendrá el amor en el carnaval.

En la segunda escena, confluyen dos vertientes míticas y festivas del folklore del Norte Argentino: la fiesta de la Chaya, o Carnaval, y el ritual del Chiqui. Los "dioses" de cada uno de estos fenómenos folklóricos son contrapuestos; sus festividades también: el Pucllay es el dios de la alegría, del desenfreno, de la libertad y de las inversiones propias del carnaval. Su representación es muy cercana a la figura común y superficial que se tiene de Baco; el Chiqui, en cambio, es una deidad funesta, oscura y vengativa. Incluso, hay testimonios arqueológicos de que, para apaciguar su posible ira, se realizaban sacrificios humanos en su honor, incluidos los sacrificios de niños (cf. Quiroga 1992: 325 ss.) 7 . Una inmediata observación emerge: en la fiesta del carnaval, de la alegría, Chiqui, deidad adversa, de la fatalidad, no tiene cabida natural. Para dar entrada a una energía funesta en la alegría del carnaval, el dramaturgo construye el prólogo, una explicación actuada en la cual se encuentran y dialogan Chiqui y Pucllay, rodeados de una atmósfera coral y de danzas agrestes que dejó la primera escena. Técnicamente, el dramaturgo fusiona la desgracia con la alegría, una suerte de justificación de que ocurra una desgracia dentro del carnaval. Sin embargo, un hecho funesto dentro de una fiesta alegre sería fácilmente verosímil sin este recurso técnico del prólogo dramático. La razón de estas escenas comienza a tomar consistencia justamente en la evocación del teatro antiguo. Es notable, en relación con esto, la necesidad de explicar que tiene el autor en notas y acotaciones, y lo hace tomando como referencia parámetros de la cultura clásica. Por ejemplo: "el 'Pucllay' recuerda un poco al Dionisos griego, a Baco en sus últimas transformaciones" (Prol.); "En la luz espectral, los troncos y las ramas se verán como torsos y brazos de sátiros” (Prol.). Evidentemente, está proponiendo equivalencias entre la cultura antigua y los elementos de la local. Al indagar sobre la primera formación literaria y las lecturas de Ponferrada, encontramos un libro clave al respecto: Les deux masques (1880) de Paul de Saint-Victor ${ }^{8}$. El dramaturgo, al parecer, aprovechó muchos conceptos contenidos allí para evocar y dotar a su obra de una dimensión pre-teatral con respecto a que la tragedia se habría originado en las fiestas dionisíacas. Los tres primeros capítulos están destinados al origen de Baco, las diversas transformaciones y su relación con el nacimiento de la tragedia. Dentro de ellos, encontramos

\footnotetext{
${ }^{7}$ La figura del Chiqui envuelve matices mucho más complejos de los que podemos abarcar aquí para nuestros fines literarios. Véase Gentile, 2001.

${ }^{8}$ Este libro hoy es considerado poco científico en su campo, pero fue muy leído y consultado en la época de Ponferrada como un manual abarcador del teatro del mundo. En nuestra opinión, sigue siendo de agradable lectura.
} 
numerosos conceptos que, tomados como ideas motivadoras, pudieron servir al dramaturgo para la composición del Prólogo y la dimensión simbólica que aporta éste a la interpretación de la obra. Son numerosas las afirmaciones de Saint-Victor que pueden relacionarse tanto con el "Prólogo" como con diversas partes de El carnaval del diablo. Sólo por dar algunos ejemplos, Saint-Victor presenta Bacos propicios y funestos (1943: 27); el ingreso de este dios a la Hélade fue como un buen genio campestre (28) y todas las obscenidades del celo universal toman su forma (30); relacionados con él están los sátiros, silvanos, aegipanes (31); el Baco-Zagreo "sedujo al hombre por la alegría" (40) pero tiene un lado oscuro e infernal, es decir, tiene potencia destructora con la apariencia de dulzura, y la vida y la muerte se confunden en sus brazos (41); Baco era dios de la alegría, asimismo dios del dolor y "su culto debía ser, por excelencia, el que más agitase a las almas, arrebatándoles en la alegría y sumiéndolas en la tristeza. La hilaridad y la aflicción, las carcajadas jubilosas y los torrentes de lágrimas encerrábanse en el vino que escanciaba a los hombres. Trágico [y al mismo tiempo] cómico" (55); "las mismas Bacanales tenían su aspecto lúgubre, su faz desolada. Al mismo tiempo que se sublimaban las delicias y las generosidades y las munificencias y las voluptuosidades del dios, se lloraba por los infortunios. En algunas ocasiones, el vino parecía ensangrentar las copas [...]. Baco, rey de la tierra, reinaba también en los infiernos y su divinidad fúnebre proyectaba sombra de muerte sobre estos triunfos de la vida" (57).

Ponferrada parece haber intentado reconstruir con elementos folklóricos del Norte argentino y de la región andina este Baco múltiple, con el fin de que reuniera facetas opuestas de manera simultánea.

El Prólogo, aún sin haber iniciado el carnaval, se introduce con un coro y con danzas agrestes. Las acotaciones del dramaturgo vuelven a darnos pruebas sobre lo que estamos investigando:

Dos semicoros estarán adelante, a la derecha e izquierda. Serán grupos de ancianos y de ancianas, respectivamente, y sus voces se oirán como el eco tardío de la experiencia y de la reflexión. Las partes de los dichos semicoros han de ser siempre habladas. En cambio, el coro tendrá invariablemente una función cantante (que es la del cancionero popular, porque en el cancionero popular-si la vida es teatro- parece haber quedado lo que era el Coro en la Tragedia antigua) (Prol.)

Es evidente, al explicar los elementos folklóricos que incorpora, que ha intentado equiparar funciones existentes en la tragedia antigua. La forma en que todos estos elementos se unen en el "Prólogo" va a determinar una dualidad interpretativa en toda la obra y empujará el desarrollo hacia el final trágico.

Por las acotaciones del dramaturgo, las dos escenas del Prólogo están sumergidas en una atmósfera báquica. La primera, dominada por el coro, sugiere una trama erótica con acciones que dejarán culpa, y se desarrolla alrededor del algarrobal, sus frutos y su bebida etílica: 


\section{Mozo PRimero}

¡Bienhayga el árbol macho!

¡Tronco y raíces firmes...!

Moza PRimera

¡Busco un querer que tenga

Su fuerza y sus raíces...!

Primer semicoro

Amor dulce y seguro,

Lo mismo que sus ramas

Con el fruto maduro.

[...]

Primer semicoro

De la algarroba

Salen beso y cariño,

Baile y aloja.

Mozo cuarto

Te llevé a la sombra...

Te echaste a llorar...

Moza cuarta

¡La culpa la tuvo

Don Juan Carnaval...!

Esta primera escena se inicia con la entrada del coro y del semicoro, y termina con el alejamiento de ambos. El diálogo entre ambos sugiere la historia amorosa con asomo de culpa que se inició en tiempos de carnaval.

La escena segunda presenta un diálogo de dioses opuestos: Chiqui y Pucllay; sin decirlo explícitamente, resulta una explicación para que el público entienda y vea justificadas las acciones dramáticas del resto de la obra, pues la presencia de ambos teñirá la fiesta de una atmósfera tragicómica. Sin embargo, durante los cuatro actos no serán personajes de mucha participación, como en el Prólogo, sino presencias determinantes 9 .

\section{Chiqui}

Entre los dos podríamos buscar

La manera mejor de descansar,

${ }^{9}$ Podemos señalar como una excepción la esc. II del Act. IV, donde, en sueños, el verdadero Pucllay intervendrá en una danza de seducción en la cual le disputa el amor de Isabel a Rosendo, su joven enamorado. 
De amenizar, diré, nuestro destino.

[...]

Pucllay

Tiene razón, compadre, es aburrido

Vivir así. Y ya se me ha ocurrido

Que poniendo las cosas al revés

Va a ser más divertido.

Dígame: si cambiara su tristeza

Por lo que todos dicen es mi gozo, ¿se sentiría feliz?

\section{Chiqui}

¡Velay, dichoso

Como ir de la miseria a la riqueza!

Pucllay

Bueno, le cedo mi felicidá; (sic)

Y para mí será lo pertinente

Verme así, convertido redepente (sic)

En señor de la fatalidá... (sic)

\section{Chiqui}

¿Sabe que no está mal?

\section{Pucllay}

¡Qué va a estar!

¡Si al menos tiene un poco más de gracia

Que sea usté (sic), tan luego, el carnaval

$\mathrm{Y}$ yo quien les reparta la desgracia...!

\section{Chiqui}

¡Eso es vida!

Pucllay

Pero hay que darse prisa;

Hay que cambiar de aspecto agora (sic) mismo.

Pongasé usté (sic) mi mascarón de risa,

Demé su cara de... ¡de fatalismo!

De este modo, quien presidirá el carnaval durante la fiesta será el Chiqui con máscara de Pucllay, es decir: la fatalidad con aspecto de felicidad. Será el carnaval del diablo, conjunción de la que no puede esperarse más que una tragicomedia. Este cambio de máscara hace que parezca lo que no es, es decir, 
parezca la alegría y sea la fatalidad. El verdadero Pucllay no tendrá cabida en la obra salvo como apariencia. Dicho de manera menos figurada, la fiesta tendrá toda la apariencia y la forma de la alegría, pero será conducida hacia lo fatal. En la trama principal, esta dualidad se transfiere a la protagonista María Selva y llega hasta el sacrificio humano de su hija Isabel, quien es muerta por su enamorado, pero sin querer y en circunstancias que ni él mismo comprende:

Rosendo

¡No la quise matar...! ¡Juro que no...!

¡Por mi madre...! ¡Por Dios...! ¡Yo estaba ciego!

Apenas vi la sombra de un jinete...

¡Fue la fatalidad la que hizo fuego...! (Act. IV esc. XIV)

Ante esta desgracia, María Selva asume toda la responsabilidad del hecho:

María Selva

[...] Es mi castigo. El último...

¡Yo la he matado a mi hija...!

¡Sombra de malquerencia sin sociego...,

Sombra perseguidora y perseguida...!

¡Maldita sea la áspera semilla

Del primer hombre que sembró mi vida,

Y la entraña que dio fuerza ciega

Para que germinara en cosa viva...!

¡Maldita sea la sangre de mi sangre,

Río de sufrimientos, triste río...!

¡Maldita el agua oscura y dolorosa

Derramada en la tierra de los hijos...!

(Se volverá a Rosendo con dolorosa ternura)

¡Muchacho...! ¡Pobre niño atolondrado....!

Todo lo que ha pasado es mi destino; (Act. IV esc. XIV)

Toda esta desgracia alivia, purifica a María Selva y al entorno (“iQué lindo amanecer!" dice María Selva). Con su vertiente religiosa cristiana, El carnaval del diablo es también una lección a través del ejemplo (cf. Rodríguez Adrados 1999: 34): el hijo concebido durante el desenfreno del carnaval acarrea la desgracia como un castigo; el carnaval lo engendra y el carnaval lo mata. La desaparición de Isabel, que era la misma materialización del pecado, por más doloroso que sea, libera la opresión de la culpa.

\section{Conclusiones}

En El carnaval del diablo son muchos los elementos que arraigan en la 
tradición del teatro clásico, principalmente, los de la tragedia griega. Hemos enumerado los más sobresalientes y, por razones de espacio, nos detuvimos en el breve prólogo, que reúne conceptos fundamentales para el desenlace trágico de la obra. Desde ese primer momento de la obra, se hace notable el esfuerzo del dramaturgo por vincular las tradiciones clásicas con las del Norte argentino, tomando como fiesta popular central el carnaval de la cultura andina. Por esta combinación, logra reinstalar en su obra elementos pre-teatrales, guiado sin duda por las lecturas sobre el origen del teatro de Paul de Saint-Victor, cuyo libro, Les deux masques, le proporcionó conceptos que le sirvieron para transformarlos en técnica teatral. Los elementos ya presentes en el Prólogo dramático (el coro y el semicoro, en los que recae la reflexión y la lírica popular, el marco agreste, el entorno festivo, los dioses que dialogan e intercambian sus máscaras, la prefiguración del destino trágico, etc.), condicionan la comprensión de la obra y la vinculan con aquellos elementos que a lo largo del tiempo han sido relacionados como parte del origen del teatro occidental: fiesta popular, tema colectivo, un drama que pertenece a una comunidad, con su lección "moral", con danzas, cantos corales, recitados líricos, disfraces y máscaras. El componente más notable es la construcción de un Baco localizado en el Norte argentino, que fuera propicio y funesto a la vez: el Chiqui-Pucllay. Ponferrada dramatizó el carnaval, la fiesta del Norte más rica y compleja desde el punto de vista antropológico, para convertirla en una tragedia (o mejor, tragicomedia) al estilo de los orígenes y primeras manifestaciones del teatro griego. 


\section{Bibliografía}

Aristóteles (1974), Poética. Edición trilingüe, trad. García Yebra, V. Madrid: Gredos.

Barcia, P. L. (2007), "La obra de Juan Oscar Ponferrada", in AAVV Homenaje a Juan Oscar Ponferrada. Catamarca: Secretaría de Estado de Gabinete.

Bieber, M. (1961), The History of the Greek and Roman Teather. Princeton-New Jersey: University Press.

Castellani, L. (1945), Críticas Literarias. Notas a caballo de un país en crisis. Argentina: Dictio.

Cortazar, A. R. (1949), El carnaval en el folklore calchaquí. Buenos Aires: Sudamericana.

De Saint-Victor, P. (1880), Les deux masques. Tragédie - Comédie. I. Buenos Aires: Calmann Lévy, Éditor.

De Saint-Victor, P. (1943), Las dos carátulas. Buenos Aires: Juaquín Gil Editor.

Gentile, M. E. (2001) "Chiqui: etnohistoria de una creencia andina en el noroeste argentino", Bulletin de l'Institut Français d'Études Andines 30. 1: 27-102.

Herrera, E. (2007), "La idea del destino según los personajes de El carnaval del diablo". Jornadas de Homenaje a Juan Oscar Ponferrada: Universidad Nacional de Catamarca, junio de 2007. Material inédito cedido por la autora.

Monayar, J. H. (1993), “Juan Oscar Ponferrada. Su teatro”, in Calás de Clark, M. R. (ed.), Historia de las Letras en Catamarca. II. Catamarca: EDICOSA.

Ponferrada, J. O. (1958), El carnaval del diablo. Buenos Aires: Ediciones del Carro de Tespis.

Ponferrada, J. O. (1970), Tres obras dramáticas. Buenos Aires: Eudeba.

Quiroga, A. (1992), Calchaqui. Buenos Aires: Tea.

Rodríguez Adrados, F. (1972), Fiesta, tragedia y comedia. Sobre los orígenes griegos del teatro. Barcelona: Planeta.

Rodríguez Adrados, F. (1999), Del teatro griego al teatro de hoy. Madrid: Alianza.

Tacconi, M. C. (2004), “Tradición mítica y tradición literaria en El Carnaval del diablo de Juan Oscar Ponferrada”, en Videla de Rivero, G., Castelino, M. E., Literaturas de las regiones argentinas. UNCuyo. 